\title{
Differences between CBCT devices to measure buccal-bone thickness after implant placement
}

Bohner L, 1,2 Marotti J,2 Chilvarquer I, ${ }^{3}$ Tortamano P

1 Department of Prosthodontics, University of São Paulo - São Paulo, Brazil

2 Department of Prosthodontics and Biomaterials, Center for Implantology, RWTH Aachen University - Aachen, Germany

3 Department of Radiology, University of São Paulo - São Paulo, Brazil

\section{Abstract}

Cone-beam computed tomography (CBCT) has been widely used to evaluate perimplant bone parameters in a tridimensional visualization. However, artifacts occur in the presence of metal objects and may affect the image quality of dental implants ( surrounding dental implants. Dental implants ( $\mathrm{n}=17$ ) were installed in dry human skulls

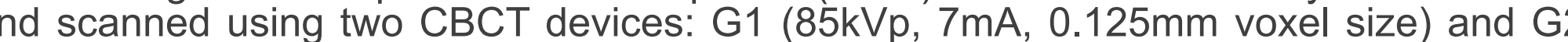
$(70 \mathrm{kVp}, 6.3 \mathrm{~mA}, 0.180 \mathrm{~mm}$ voxel size). Buccal bone thickness was measured at points A): apical of dental implant; (B): $5 \mathrm{~mm}$ above point $A$ and (C): distance between top of mplant to the bone surface. Values were compared with a high-precision compute

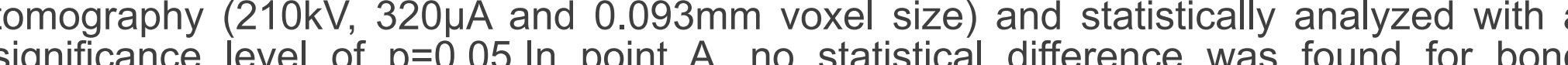

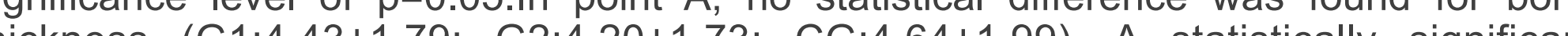

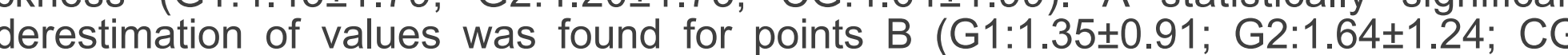

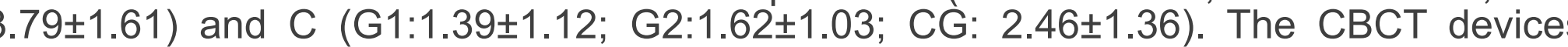
presented similar accuracy for measurement of buccal-bone thickness surrounding dental implants.

\section{Background and Aim}

Cone-beam computed tomography (CBCT) has been widely used to evaluate peri-implant bone parameters in a tridimensional visualization. However, artifacts occur in the presence of metal objects and may affect the image quality of dental implants surroundings. The purpose of this study was to evaluate the accuracy of two CBCT devices for measurement of buccal-bone thickness surrounding dental implants.

\section{Methods and Materials}

\section{Study design}

Dental implants $(n=17)$ were installed in maxilla of 6 dry skulls and scanned with two CBCT devices and a high-precision computed tomography. Bone thickness was measured at points (A): apical of dental implant; (B): $5 \mathrm{~mm}$ above point $\mathrm{A}$ and (C): distance between top of implant to the bone surface.
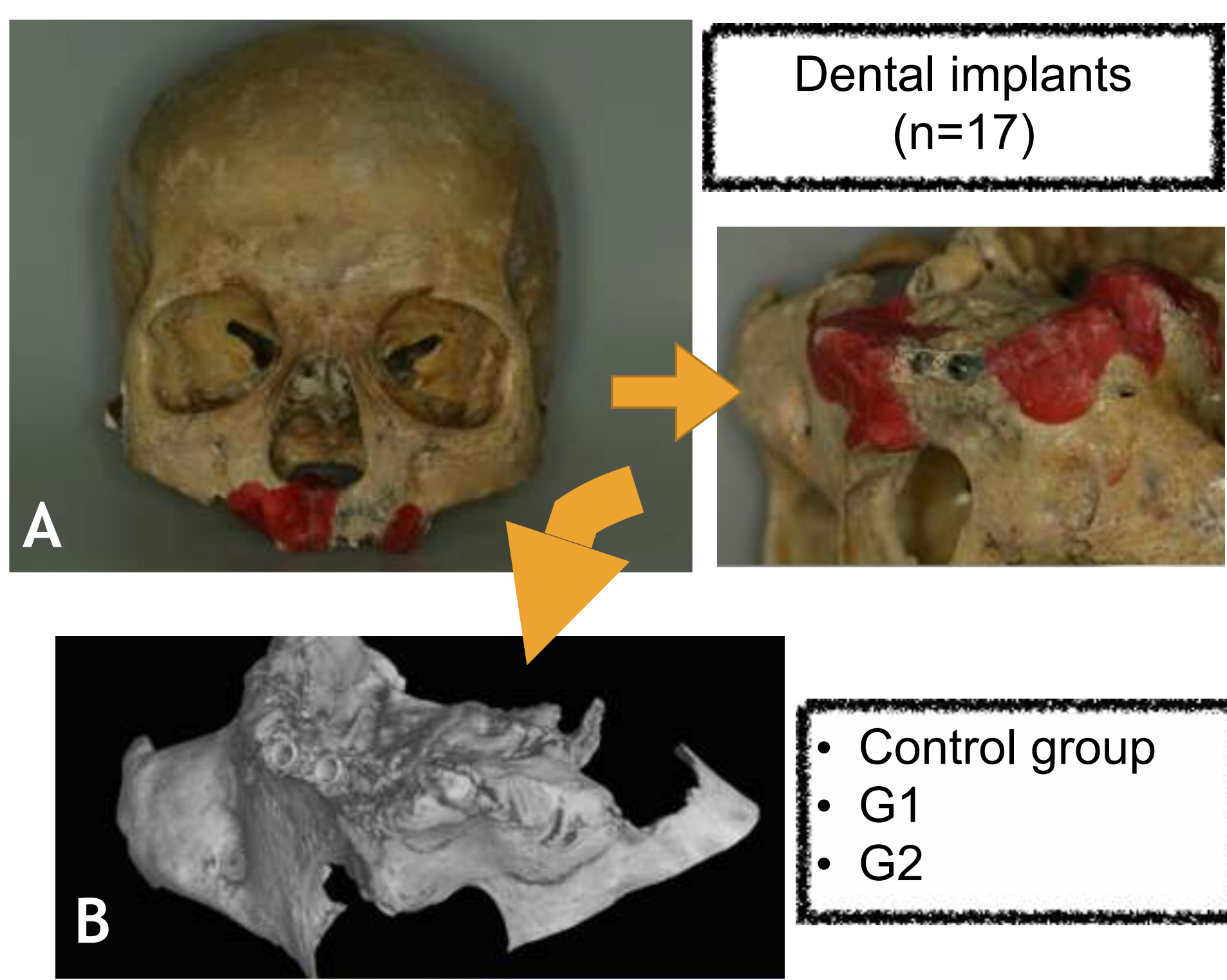

- Control group

\section{- G1}

- $\mathrm{G} 2$
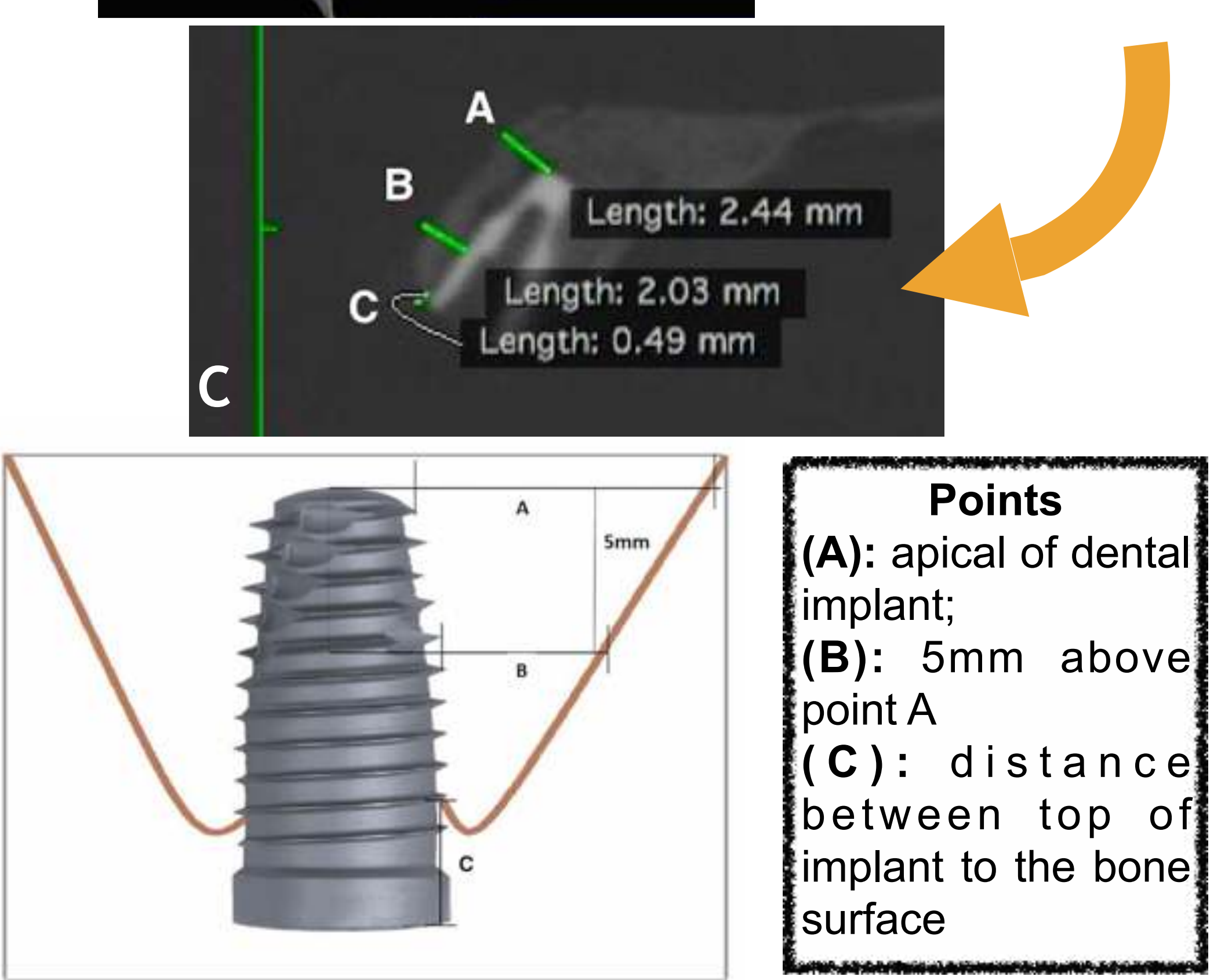
Figure 1. (a) Dry skulls used in this study. (b) Acquisition of CBCT images and
measurement of bone thickness. (c) Bone thickness determined in (A) the apical portion of the implant;. (B); $5 \mathrm{~mm}$ above and (C) implant platform.

\section{Control Group}

Values were compared with a high-precision computed tomography $(210 \mathrm{kV}, 320 \mu \mathrm{A}$ and $0.093 \mathrm{~mm}$ voxel size)

\section{Test Group}

- G1: CBCT J. Morita, USA

- G2 : CBCT Carestream Health, USA

Table 1. Description of CBCT devices

\begin{tabular}{ccccc}
\hline CBCT & $\begin{array}{c}\text { Tube voltage } \\
(\mathbf{k V})\end{array}$ & $\begin{array}{c}\text { Tube current } \\
(\mathbf{m A})\end{array}$ & $\begin{array}{c}\text { Field of } \\
\text { View }\end{array}$ & $\begin{array}{c}\text { Voxel size } \\
(\mathbf{m m})\end{array}$ \\
G1 & 85 & 7 & $8: 8$ & 125 \\
G2 & 70 & 6.3 & $8: 8$ & 0.18 \\
\hline
\end{tabular}

\section{Results}

Table 2. Mean (SD) from bone thickness determined by control group (GS) and $\mathrm{CBCT}$ devices (G1 and $\mathrm{G} 2$ ) for different points (Point A, B and C).

$\begin{array}{cccc}\text { CBCT devices } & \text { Point A } & \text { Point B } & \text { Point C } \\ \text { CG } & 4.64(1.99) & 3.79(1.61) & 2.46(1.36) \\ \text { G1 } & 4.43(1.79) & 1.35(0.91) & 1.39(1.12) \\ \text { G2 } & 4.64(1.99) & 1.64(1.24) & 1.62(1.03) \\ \text { p value } & >0.05 & <0.05 & >0.05\end{array}$

Bone thickness $(\mu \mathrm{m})$

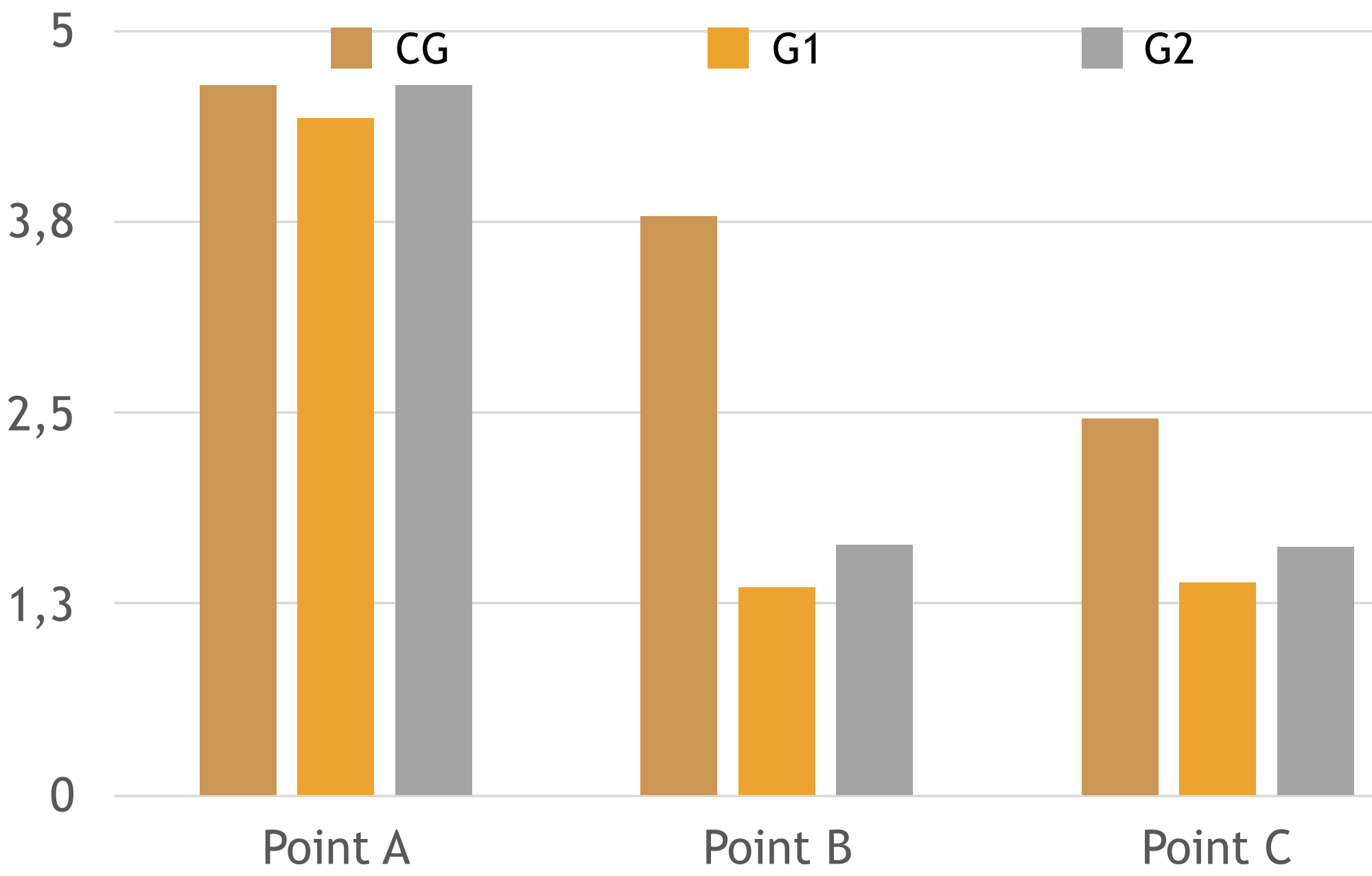

Figure 3. Mean differences among groups for points $A, B$ and $C$.

\section{Conclusions}

The CBCT devices presented similar accuracy for measurement of buccal-bone thickness surrounding dental implants.

\section{References}

Measurement of buccal bone volume of dental implants by means of cone-beam computed tomography, Clinical Oral Implants Research.

2. Dental Cone-beam computed tomography analyses of the anterior maxillary bone thickness for immediate implant placement, Implant Dentistry.

3. The influence of exposure parameters on jawbone model accuracy using cone beam CT and multislice CT, Dentomaxillofacial Radiology. 